\title{
The Challenges and Prospects of Building Sustainable Peace and Security in the Horn of Africa
}

\author{
Efa Tadesse Debele \\ Department of Sociology, College of Social Sciences and Humanities, Samara University, Samara, Ethiopia \\ Email address: \\ efatdss@gmail.com \\ To cite this article: \\ Efa Tadesse Debele. The Challenges and Prospects of Building Sustainable Peace and Security in the Horn of Africa. International Journal \\ of Sustainable Development Research. Vol. 4, No. 3, 2018, pp. 44-46. doi: 10.11648/j.ijsdr.20180403.11
}

Received: November 2, 2018; Accepted: December 22, 2018; Published: January 22, 2019

\begin{abstract}
The purpose of this study is to investigate the challenges and prospects of building sustainable peace and security in the horn of Africa. The study dedicates to explore effective ways to achieve promising peace and security scheme.Some studies revealed that study area is being challenged by intractable conflicts. However, IGAD is doing its best to restore peace and security in the region. Member States started to cooperate each other for this common good. Despite this effort, the ever increasing internal and external conflicts and war challenged the peace progress. This is mainly due to member states of horn of Africa did not pay adequate attention towards local communities. The communities are not architect of the road map and they are not vanguards in implementing the peace and security framework. This scenario intensifies the conflict to grow into intractable conflict. Thus, for the sake of building sustainable peace and security in the horn of Africa it is high time to reexamine the prior approaches and make sure that local communities are main actors in the peace and security project or framework.
\end{abstract}

Keywords: Challenges and Prospects, Peace and Security, Horn of Africa

\section{Introduction}

Currently, the social world is undergoing a great peace crisis.For example, horn of Africa is a region that nowadays confronting with a peacecrisis and security problems. Instability and insecurity has the potential to transform ordered patterns and posesocial chaos and uncertainity. Yet,effort is being madeto alleviate the problem and to create humanitarianly conducive region.

A number of countries are combined to describe the geographical area termed as Horn of Africa. Accordingly, Djibouti, Ethiopia, Eritrea, Kenya, Somaliland, Sudan, andSouth Sudan are constituting countries. The region is undergoing dynamic conflict and social disorder. The horn of Africa countries are always in stress and tension partly due to rivalries among them on the resources of the region.This scenario of rivarly process always undergoes dynamic repercussion.

The purpose of this study is to investigate the challenges and prospects of building sustainable peace and security in horn of Africa. The study area is highly undergoing a drastic and extensive conflict trends which is induced by internal and external factors. In fact, the study area is composed of multicultural societies that have their own interests and needs.

The conflicting scenario of region in general, and its repercussion in particular results in several catastrophes. In the aforementioned region, social unrest process is increasing tremendously. The study area is extremely experiencing internal conflicts, interstate conflict and terrorismsymptoms. Hence,researcher believed that the detailed nature of these problems deserve a rigorous study.

The peace and security scenario in the horn of Africa in general and wthin individual state in particular inherited with its challenges and prospects. EventhoughIntergovernmental authority on Development (IGAD) brought opportunities in the region so as to build peace and security, it has failedto meet its vision and ultimate goal.

Instability in the horn creates challenges for each state so far no particular attention paid to bring sustainable peace and security. Currently, war and terrorism are the main problems of the region. Thus, the current conflict trend creates fortune for terrorists and harm the majority of the societiesof the horn who are incapable of defending themselves frominsecurity character partly due to their susceptibility. 
The study area is expected to face several complicated and tremendous challenges unless the challenges are identified and controlledbefore escalation. The international and local organization are doing something in the region so as to retain peace and security to ensure its sustainability without taking into account the local community'sreaction and full participation. For this reason, the region exposed to several dilemma which need meticulous investigation.

The general objective of this research is to investigate challenges and prospects of building sustainable peace and security in the horn of Africa.

The specific objectives of the research are:

a. to examine challenges that hinder the region's peace and security condition,

b. to investigate prospects can be utilised in the course of ensuring peace and security,

c. to identify possible ways or strategies that help realisation of sustainable peace and security in the Horn of Africa.

\section{Methodology}

The Greater Horn of Africa, as defined by the Intergovernmental Authority on Development (IGAD), comprises eight countries (Djibouti, Eritrea, Ethiopia, Kenya, Somalia, South Sudan, Sudan and Uganda).Horn of Africa, which is the the strategic political position, has been characterised by its instability and insecurity. Recently,Intergovernment authority of Development is trying its best to improve the region's peace and security scenario.

The researcher employed qualitativeresearch design. This wasdonethrough documentary research and key informant interview.

The primary data of this research were collected through key informant interview. The secondary data that were extracted from research work entails reports, articles, magazines, brochures, newspaper, books, etc.The qualitative data obtained through predetermined data collection tools were analyzed using appropriate methods of analysis.

\section{Results and Discussion}

\subsection{Challenges}

Some studies indicated that the horn of Africa is the most perplex and unstable regions of this world. The source of this crisis is both internal and external factors. [1]Annan (2014) found that bad governance, corruption, human rights violations, poverty, ethnic marginalization, small arms and light weapon proliferation as triggers and drivers of violent conflicts. On the other hand, [2] Zeleza (1992) mentioned that ethnic rivalries, polarizations, economic underdevelopment and inequalities, poor governance and past experiences as factors. In line with this theme [3] Olaosebikan (2010) reported that border issue, ethnic composition, poor leadership, corruption, negative effects of external debt burden and poverty are causes for the conflicts.
In line with this challenges scholars such as [4] Grasa et al.(2010), [5] Wodrow (2011) and [6]Cocodia (2016) suggest African problems by Africans.

Peace building challenges of Horn of Africa are including genocide, war crimes, and crimes against humanity, electoral violence, transitional justice, on- and off-shore terrorism, and the unlawful use of marine resources [7] (Alemayehu, 2011). [8] Solomon (2014) also identified that undemocratic governance, poverty and low levels of development, a political culture of (in)tolerance and lack of respect for the rule of law are factors. [9] Olu (2015) saw vested interests of member countries and override the shared interests of the region that contributed to the limitations on the IGAD integrative arrangement.

\subsection{Prospects}

Another study indicates that if there is cooperation between countries of Region in all aspects specially food security, good governance, conflict transformation and protection for humanitarian aspects then building peaceful and well secured region is realistic. Nowadays, IGAD is striving for common good and better region realisation. In this regard [10] Annan (2014) stated that rich indigeneous cultural values like respect, freedom, cooperation and tolerance can be harnessed and realize its vision. IGAD also promise for prevention, management and resolution of conflicts [11] (Alemayehu, 2011). [12] Solomon (2014) also states that IGAD has opportunity to ensure peace and security that confirmed by Olu (2015).

\subsection{Possible Way Outs}

In this regard several scholars propose different idea. Similarily Local and internatioonal Governmental and Non governmental organization presented so many solutions. The point is, however, how this problem yet not solved effectively. This may suggest that approaches that have been followed need to be reconsidered and re-examined. As historically seen our political culture missed something very essential. This is lack of legitimacy and public orientation. People are potential enough to react towards their problem by generating problem solving idea and taking action by their own. This demands public mobilisation and empowerment what previously trends missed during their attempt to solve the problem.

The governments do not consider local community as part of solution rather they stick to top bottom approach. This kind of scenario repeatedly proved not working and ineffective. When we consider horn of Africa people are always suffering from instability and social disorder. Local and international actors tried to solve this problem by their way. Nevertheless, yet the problem is escalating. Thus, those local, regional and international actors need to think differently. Because, the existing approaches and trends do not result in promising outcome.

In nutshell for this peace and security problem let local people sensitive of the problem and invite them to the platform of peace dialogue. Let them generate solution and 
make sure them to be committed to fix the problem. This further require approach shift from top bottom to bottom up paradigm. Unless the region may not be free from intractable conflict. Empowering local community and mobilising them positively impact the status of regional peace crisis. Therefore, the future attempts of ceasefire need to look into grassroot actors that can help sustainable peace and security building in the horn of Africa.

Letting people forefronts in peace and security building not only solve the crisis but also lay solid ground for its sustainability. The more the people engage in solving their problem the less the problem endure. Thus, it is high time to search local solution for local problem. This can save a lots. The futurity of horn of Africa's peace and security should be determined by communities of the region themselves. This does not mean cooperation and collaboration from others is unnecesary. It is to mean that local people should be vanguards.

\section{Conclusion and Recommendation}

The horn of Africa peace and security issue is very troubling and demanding problem. The member states have been striving for their common agenda of securing the region. Nevertheless, the efforts do not result in promising outcome. Most of the policies and strategies of these states neglect the local communities in making them architect of the roadmap and implementers of the peace and security framework.

In order to address this issue the states of the horn of Africa should cooperate each other and consolidate their solidarity. Thereby they can make sure the stability and security of the region. More importantly, the states need to invite the local people into the platform and mobilise them towards the common ajenda of securing the region socially, politically and economically. International actors need to support the local communities campaign in terms of material or financial and technical.

\section{References}

[1] Alemayehu Fentaw. 2011. Africa;Transcend Media Service; The Emerging Peace and Security Architecture in the Horn of Africa: Prospects and Challenges.
[2] Annan, N., (2014). Violent Conflicts and Civil Strife in West Africa: Causes, Challenges and Prospects. Stability: International Journal of Security and Development. 3(1), p.Art 3. DOI: http://doi.org/10.5334/sta.da.

[3] Cocodia Jude. 2016.The African Capacity for ImmediateResponse to Conflict and the AfricanStandby Force: Options for PeaceIntervention in AfricaNiger delta university, Nigeria, April 2016;social science research council | working papers;African peace building network apn working papers: no. 7.

[4] Grasa, Rafael. M, Oscar. 2010. Conflict, Peace and Security in Africa: an Assessment and New Questions after 50 Years of African Independence;icip working papers: 2010/08.

[5] Horn of Africa Bulletin.2010. Analyses; Context; Connections; Analyses; A Nascent Peace And Security Architecture In The Horn Of Africa; Prospects And Challenges; News And Events; Resources.

[6] Olaosebikan. J, Aremu. 2010. Conflicts in Africa: Meaning, Causes, Impact and Solution;Department of History and InternationalStudies, University of Ado- Ekiti, Ado- Ekiti, Nigeria ;E-mail: johnsonaremu2006@yahoo.com: Vol. 4 (4), Serial No. 17, October, 2010 ;ISSN 1994-9057 (Print) ISSN 2070-0083 (Online);(Pp.549-560).

[7] Olu.Ayodele, I and Dauda, Saleh.2015.Regional integration in Africa: the challenges and achievements of intergovernmental authority on development (IGAD);Department of Political Science and International Relations, University of Abuja, Abuja;International Journal of Multidisciplinary Research and Modern Education (IJMRME) ISSN (Online): 2454 6119 ;(www.rdmodernresearch.org) Volume I, Issue II, 2015.

[8] Social sciences research council. 2016. The crisis in the Horn of Africa. Accessed online by november11,2016.

[9] Solomon Dersso.2014.East Africa and the Intergovernmental Authority on Development Mapping Multilateralism in Transition No. 4; International Peace Institute (Ipi).

[10] Woodrow Wilson International Center for Scholars.2011.Pathways to Peace in the horn of africa:what role for the United states?Horn of AfricA Steering committee.

[11] Zeleza.T, Paul.1992.The Causes \& Costs of War in Africa; From Liberation Struggles to the 'War on Terror'. 